\title{
Evaluation of Grouting Condition of Post- Tensioned Concrete using R-wave Method
}

\author{
Kah Kian Cheong ${ }^{1}$ Foo Wei Lee ${ }^{1 *}$, Kah Hon Leong ${ }^{2}$, Ming Kun Yew ${ }^{1}$ and Yee Ling Lee ${ }^{1}$ \\ ${ }^{1}$ Lee Kong Chian Faculty of Engineering and Science, Universiti Tunku Abdul Rahman, Jalan Sungai \\ Long, Bandar Sungai Long, Cheras, 43000 Kajang, Selangor, Malaysia \\ ${ }^{2}$ Faculty of Engineering and Green Technology, Universiti Tunku Abdul Rahman, Jalan Universiti, \\ Bandar Barat, 31900 Kampar, Perak, Malaysia
}

\begin{abstract}
Post-tensioning (PT) system is widely used not only in bridge construction, but also used as a replacement of reinforced concrete (RC) structure for slab, beam, and wall. Nowadays, many countries around the world are focusing on sustainable development in the construction industry. PT system is one of a system which able to meet the standard of sustainable building construction. Its advantages are able to save more materials, construction time and maintenance cost. To ensure the safety of PT systems during construction, some methods are implemented to evaluate the concrete condition. In this study, the Rayleigh wave (R-wave) method is used to evaluate the grouting condition of the post-tensioned concrete structure. Useful parameters of R-wave such as amplitude, time, frequency and wave velocity are identified and obtained through a series of numerical simulations and experimental tests. Different frequencies are excited to examine the behavior of $\mathrm{R}$-wave propagated through a concrete medium with different grouting conditions in the simulation. In experimental testing, different diameters of steel balls are used as an impactor to generate waveform and the generated waveforms were recorded by the data logger. Three equidistance receivers are placed on top of the tested concrete specimen with different duct materials of aluminium duct and PVC duct embedded in it. As a conclusion, when voids are present in the concrete specimen, high readings of amplitude and dominant frequency are recorded and the travelling wave velocity is slow.
\end{abstract}

\section{Introduction}

The post-tensioning (PT) system is a pre-stressing method that has been widely applied by many countries around the world to replace normal reinforced concrete (RC) structures. Post tensioning is defined as a method of pre-stressing in which the pre-stressing steel is tensioned after the concrete has reached a specified strength while pre-tensioning is defined as a method of pre-stressing in which pre-stressing steel is tensioned before the concrete

\footnotetext{
* Corresponding author: leefw@utar.edu.my
} 
has been placed [1]. Pre-tensioning concrete has high-tensile steel tendon wires inserted between the anchorages at both ends of the casting steel or timber formwork and stretched before the concrete was poured into the mould. Nevertheless, post-tensioning concrete was cast with concrete first and then the steel tendon wires will be entered through the ducts and stretched when the concrete had developed sufficient strength to stress resistance [2].

PT structures need to be designed attentively and precisely for structural analysis, steel tendons and grout quality of the structure. Grout will be used in post tensioned concrete structures as it is injected into a duct and bonds with the steel tendons to the surrounding concrete, forming an integral as a unit [3]. Grout is a mixture of Portland cement and water, act as the last line of defence against corrosion of steel tendons [4]. Grout will develop an additional physical barrier against oxygen, water, and chloride, which is a corrosioncausing contaminant by creating an alkaline environment that passivates the steel [3]. Steel tendons are critical reinforcing elements of post-tensioned structures, which will susceptible to corrosion, proper treatment and protection are needed on the grouting condition. Common failures of post-tension bridges are corrosion of steel tendons due to deficient grout including voids, moisture in ducts, porous grout, grout segregation, soft grout, carbonated grout and high chloride content grout [5]. Formation of voids will occur in the duct due to incomplete grouting, trapped air pocket, poor grouting procedure or bleeding of grout, corrosion will happen in the steel tendons and eventually, the steel tendons will fail to sustain the extreme loading, causing catastrophic of concrete member failure [6].

To ensure the safety of PT structure, grouting condition needed to be inspected thoroughly, where the non-destructive test has played an important role to assure the quality of construction [7]. Several non-destructive tests (NDT) method has been considered by many researchers like ultrasonic, impact-echo (IE), ground penetrating radar (GPR) and ultrasonic method to detect grouting quality of pre-stressed concrete ducts $[8,9,10]$. However, these methods may have many issues to solve in applications to in-situ structures with respect to the area of measurement, promptness of testing and accuracy of the test results. In this study, the elastic wave method is adopted to evaluate the grouting condition of the concrete specimen. The elastic wave can be classified into Shear wave (S-wave), Pressure wave (P-wave) and Rayleigh wave ( $\mathrm{R}$-wave). In this subject field, the $\mathrm{R}$ wave is the main focal point to assess the internal grouting condition of a PT structure. R-wave has been extensively analysed and adopted in developing innovative non-destructive methodologies for concrete structures [11]. R-wave propagates only a thickness equal to one wavelength and it constrained near the surface of materials. It can propagate to long distances with its advantages of carrying a higher amount of energy and also lower geometric spreading [12]. R-wave has the advantages that it generates a high percentage of energy from a surface source in the form of Rayleigh wave, and the geometrical attenuation of this wave type is low due to the cylindrical shape of wavefront [13].

From the literature review, Rayleigh wave (R-wave) is a surface wave which is essentially a 1-D method assuming horizontally-layered medium [14]. The results showed that the surface wave method appears to be a good tool for quantifying the replacement ratio of ground improvement. Application of R-wave has been tested widely, like asphaltic concrete [15], ground modification with improvement columns [14], location and embedment depth of voids [16] and surface crack depth [12].

In et al. [15] concluded that high frequency R-wave scattering and propagation model can provide quantitative information about the aggregate content in the segregated area. To determine underground voids, spectral analysis of surface wave method (SASW) was introduced by Jones [17] and Ballard [18]. Figure 1 shows the schematic drawing of MASW test, where the distance between the source and the first receiver is labelled as offset and the distance between consecutive receivers is labelled as D. As conclusion of the study by Lin et al. (2017) [14] a homogenous medium becomes dispersive for R-wave 
propagation when there is a presence of void. R-wave also provides valuable information which will become an interesting tool in the future to investigate larger concrete blocks with deeper in depth and actual defects in concrete structures [12].

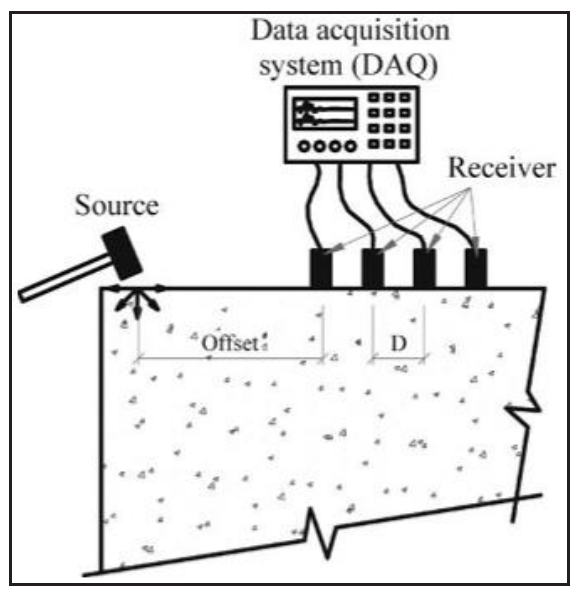

Fig. 1. Schematic Drawing of MASW Test [16]

\section{Methodology}

The motion of the elastic waves was simulated using the commercially available software and the governing two-dimensional elastic wave equation is given as equation 1 [19]:

$$
\rho \frac{\partial^{2} w}{\partial^{2} t}=\left[\mu+\eta \frac{\partial}{\partial t}\right] \nabla^{2} w+\left[\lambda+\mu+\emptyset \frac{\partial}{\partial t}+\frac{\eta}{3} \frac{\partial}{\partial t}\right] \nabla(\nabla \cdot w)
$$

Where $\rho$ is the density of the material, $\lambda$ is first lame constant, $\mu$ is second Lame constant, $\eta$ is shear viscosity, $\varnothing$ is bulk viscosity, $\nabla$ is the gradient of the operator, $\partial$ is the partial differential operator, $\mathrm{t}$ is the time and $\mathrm{w}$ is a two-dimensional column vector. A total of six cases were simulated for aluminium and PVC ducts with five different excitation frequencies, namely 5, 10, 25, 50 and $100 \mathrm{kHz}$. In addition, Table 1 shows the mix proportion used in this experiment. The design concrete strength at 28 days estimated to be $30 \mathrm{MPa}$. Ducts with fully grouted are considered as $100 \%$ grouted case while half grouted ducts are known as 50\% grouted case, as shown in Figure 2. The location of the source, receivers and the measurement array are depicted in Figure 3. For data collection of Rwaves, the experiments adopted a four-sensor array measurement for a surface crack, where $\mathrm{R}$-waves propagated through these specimens. These arrangements are defined as a linear measurement array. The steel ball impacts were implemented by the same operators so that the inconsistencies in the generation of stress waves can be minimized. Changing the size of steel ball impactors made it possible for a generation of R-waves with varying dominant frequencies. The size of the steel balls used in this study was $1.0 \mathrm{~cm}, 1.5 \mathrm{~cm}, 2.0 \mathrm{~cm}$ and $2.5 \mathrm{~cm}$. This was attempted in the investigation of the relations between dominant frequency, amplitude and velocity of R-wave when the surface crack is being filled with 
different materials at a different volume. It should be noted that a thin layer of petrol gel couplant was applied between the sensors and the specimen surface so that good acoustical coupling is ensured. For the measurements of the sound portion, ten wave excitations were conducted from one end of the measurement array, vertical crack and vertical crack filled by different volume of materials. The recorded waveforms were stacked accordingly to enhance signal persistency for further processing.

Table 1. Mix Proportion of Concrete

\begin{tabular}{|c|c|c|c|}
\hline $\begin{array}{l}\text { Cement } \\
\left(\mathrm{kg} / \mathrm{m}^{3}\right)\end{array}$ & $\begin{array}{c}\text { Water } \\
\left(\mathbf{k g} / \mathbf{m}^{3}\right)\end{array}$ & $\begin{array}{c}\text { Fine aggregate } \\
\qquad\left(\mathrm{kg} / \mathrm{m}^{3}\right)\end{array}$ & $\begin{array}{c}\text { Coarse } \\
\text { aggregate } \\
\left(\mathrm{kg} / \mathrm{m}^{3}\right)\end{array}$ \\
\hline 314.0 & 160.0 & 702.1 & 130.4 \\
\hline
\end{tabular}

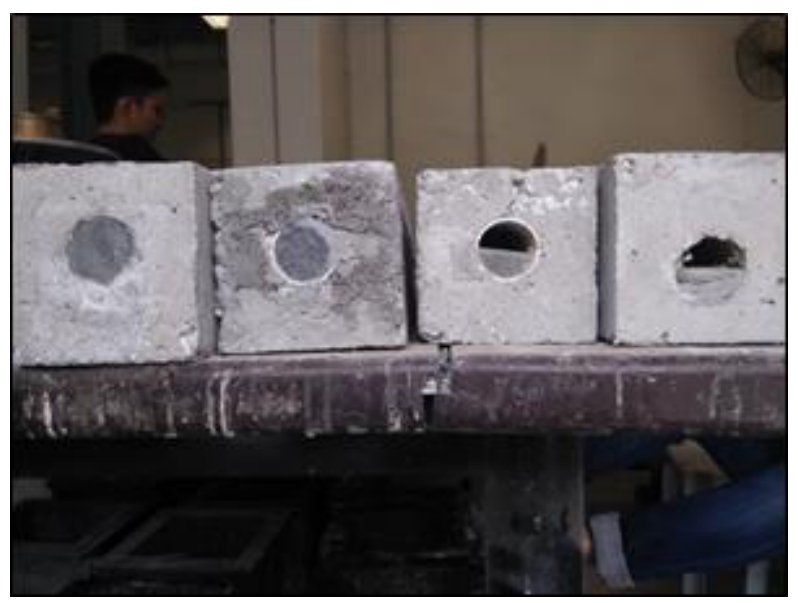

Fig. 2. Examples of experimental specimens

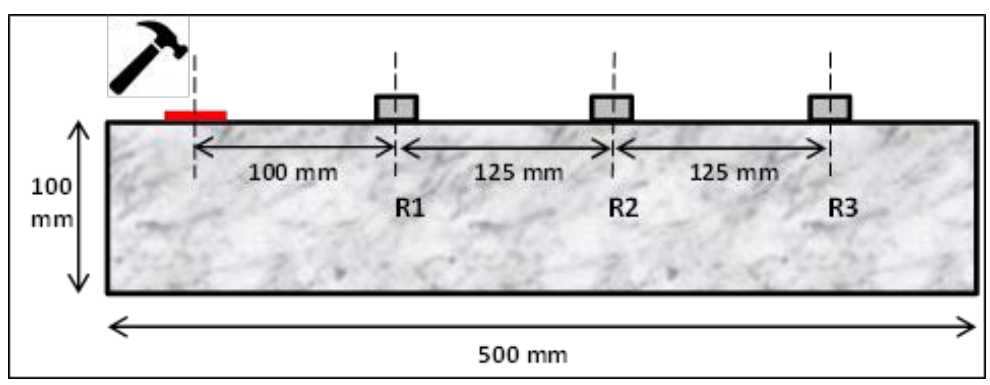

Fig. 3. Schematic sketch of the simulation model and concrete specimen

\section{Results}

\subsection{Wave velocity}


The formula for velocity is distance divided by time. The distance between the receivers was known and since the arrival time of R-peak point was determined from the amplitude against time graphs shown previously, thus the distance between receivers against arrival time of R-peak point graph was plotted and the gradient of this graph will be the velocity of the wave travelling in the respective case studies. The gradient velocities were determined and then tabulated into a graph, where every case was compared with the wave velocity travelling in sound concrete.

Figure 4 shows the simulation data when using 5 and $10 \mathrm{kHz}$ frequency, the velocity travelling in $0 \%$ grout, $50 \%$ bottom grout and $50 \%$ top grout are much lower, ranging from $1000 \mathrm{~m} / \mathrm{s}$ to $1700 \mathrm{~m} / \mathrm{s}$ as compared to the velocity travelling in sound concrete which is around $1900 \mathrm{~m} / \mathrm{s}$ to $2300 \mathrm{~m} / \mathrm{s}$. For $100 \%$ grout, the wave velocity is travelling at approximately $1500 \mathrm{~m} / \mathrm{s}$ to $2000 \mathrm{~m} / \mathrm{s}$ which is higher than the void cases but slightly lower than the sound concrete's velocity. However, using a higher frequency, such as 25, 50 and $100 \mathrm{kHz}$, the wave velocities obtained were different because higher frequency resulted to a shorter wavelength, hence the wave might not able to penetrate deep down into the concrete specimen to detect the presence of a void.

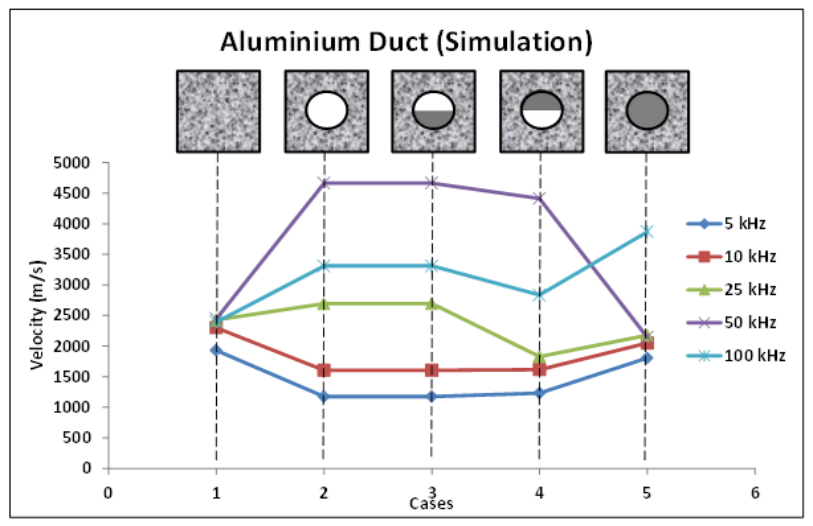

(a)

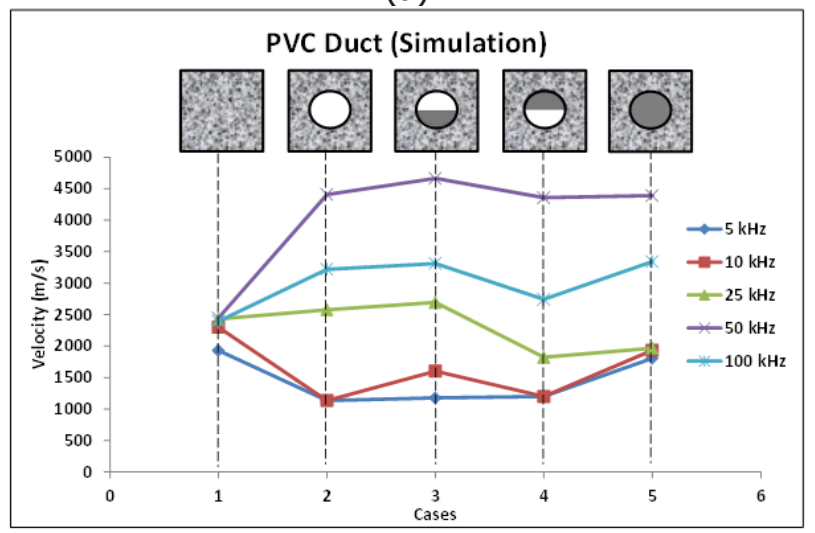

(b)

Fig. 4. Calculated velocity by different excitation frequencies for (a) aluminium duct and (b) PVC duct.

Figure 5 shows the experimental data when using a steel ball size of $1.5 \mathrm{~cm}$ and $2 \mathrm{~cm}$, the velocity travelling in $0 \%$ grout, $50 \%$ bottom grout and $50 \%$ top grout are ranged 
between $1000 \mathrm{~m} / \mathrm{s}$ to $1500 \mathrm{~m} / \mathrm{s}$, which are much lower as compared to the velocity travelling in sound concrete which is high, $1700 \mathrm{~m} / \mathrm{s}$. For $100 \%$ grout, the wave velocity is travelling at approximately $1200 \mathrm{~m} / \mathrm{s}$ to $1500 \mathrm{~m} / \mathrm{s}$ higher than the void cases but slightly lower than the sound concrete velocity.

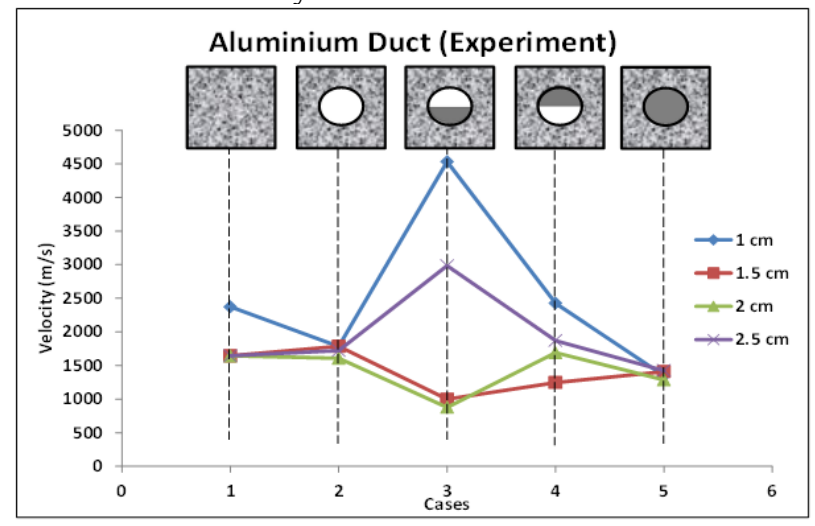

(a)

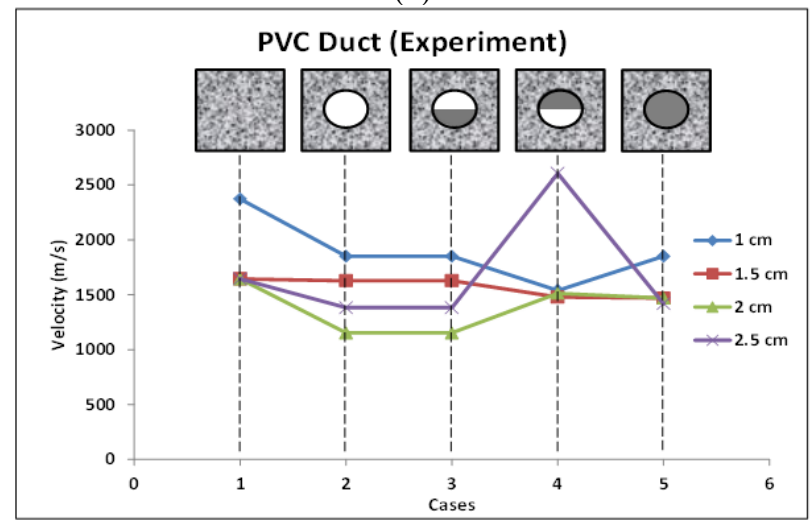

(b)

Fig. 5. Calculated velocity by different steel ball sizes for (a) aluminium duct and (b) PVC duct.

\subsection{Dominant frequency}

Dominant frequency was determined from the amplitude against frequency graphs shown previously by the maximum point in the graphs. The dominant frequency and receiver were plotted into a graph for better representable data results. The finding obtained from this comparison of dominant frequency and receivers was when voids were present in the concrete specimens ( $0 \%$ grout, $50 \%$ bottom grout and $50 \%$ top grout), the dominant frequency received by the receivers were high but low in prefect concrete specimen (sound concrete and $100 \%$ grout concrete). Figure 6 shows the simulation results using $5 \mathrm{kHz}$ as the simulated frequency, the dominant frequency recorded in prefect concrete is low $(2 \mathrm{kHz}$ $-3 \mathrm{kHz})$ whereas high dominant frequency recorded in concrete with voids $(4.0 \mathrm{kHz}-5.5$ $\mathrm{kHz}$ ). 


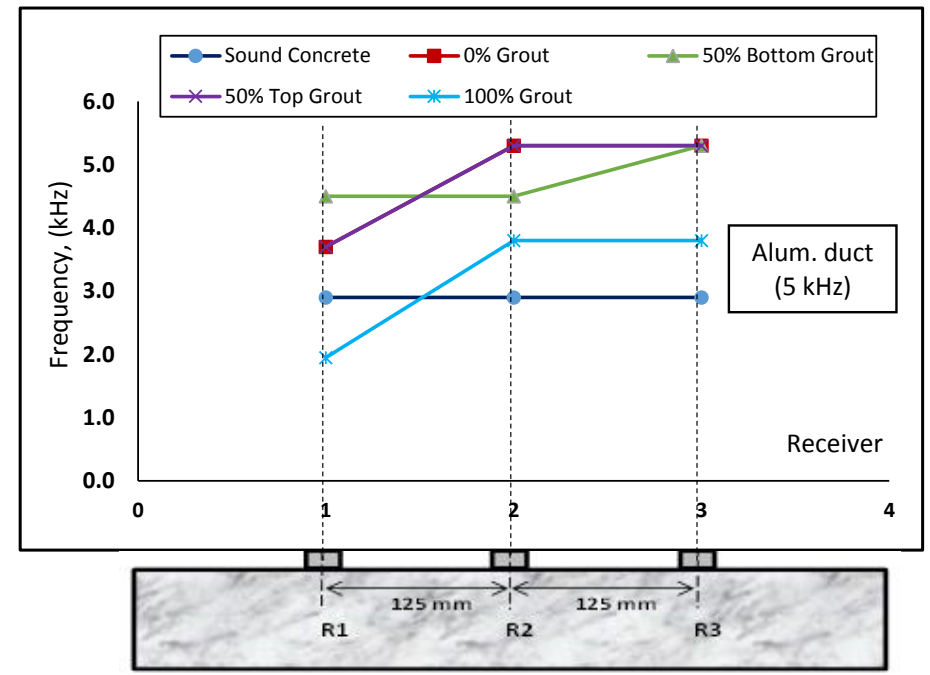

(a)

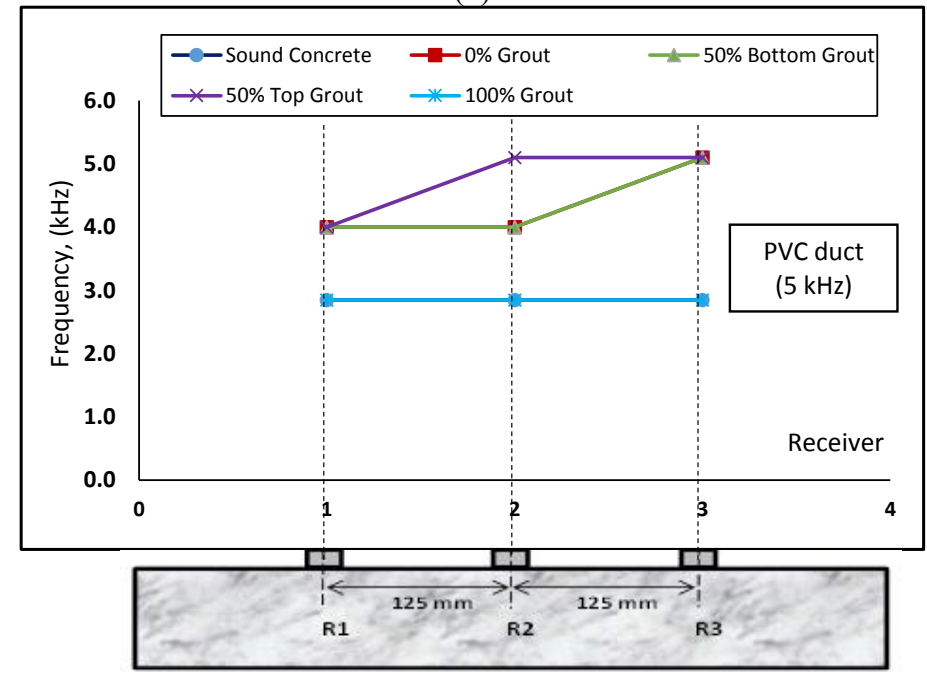

(b)

Fig. 6. Dominant frequency analysis by $5 \mathrm{kHz}$ excitation for (a) aluminium duct and (b) PVC duct.

Figure 7 shows the experimental results using $2 \mathrm{~cm}$ steel ball size as impact. The dominant frequencies in case studies of sound concrete and $100 \%$ grout were low, ranging from $1.5 \mathrm{kHz}$ to $3.2 \mathrm{kHz}$. However, for a case study of $0 \%$ grout, the dominant frequencies were high with approximately $7 \mathrm{kHz}$ to $10 \mathrm{kHz}$. 


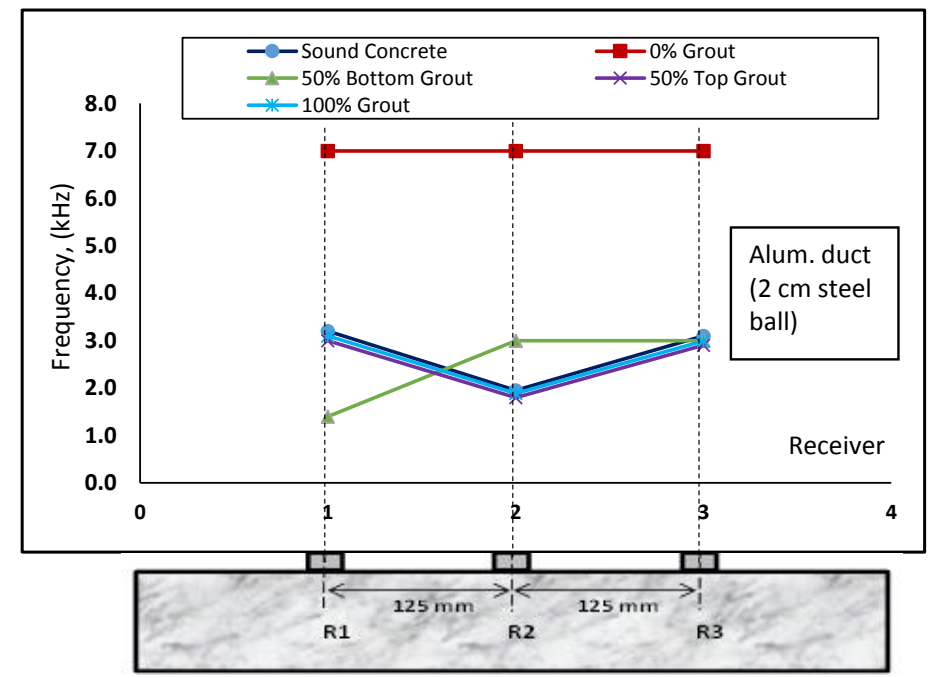

(a)

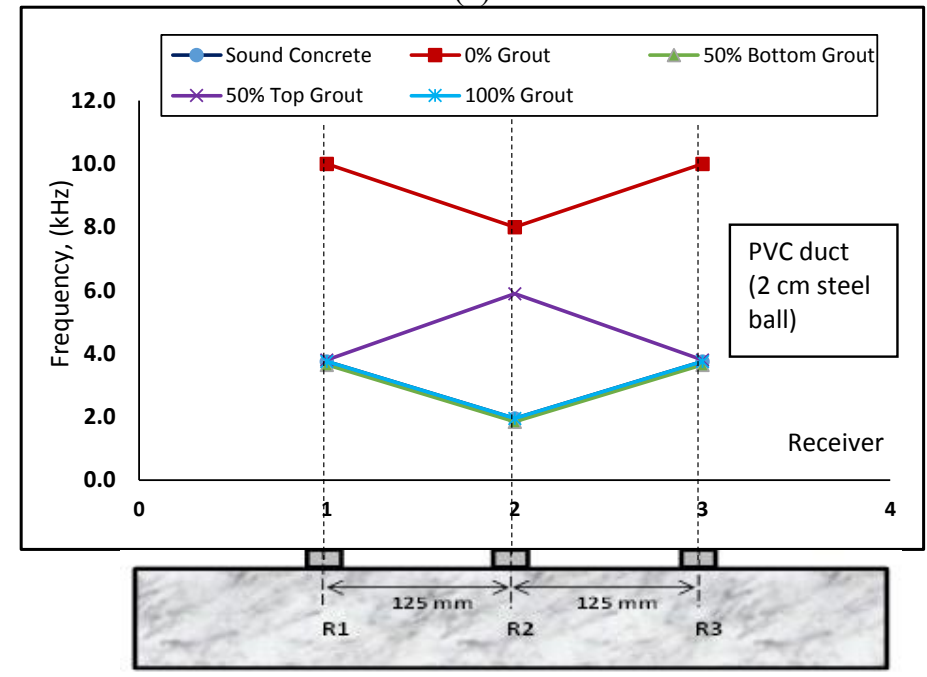

(b)

Fig. 7. Dominant frequency analysis by the impact of steel ball size of $2 \mathrm{~cm}$ for (a) aluminium duct and (b) PVC duct.

\section{Conclusion}

In this study, numerical simulation and experimental testing were conducted to investigate the behavioural change of R-waves propagating in plastic and aluminium ducts of posttensioned concrete with different grouting conditions. By adverting to the results shown, there were not many changes of R-waves behaviour propagates through different duct materials when the same simulated frequency or steel ball size was used. From this study, the useful parameters of the $\mathrm{R}$-waves sensitive towards a change of grouting conditions were analysed and identified, such as:

1. Dominant frequency: Concrete with voids has a high dominant frequency (more than $4 \mathrm{kHz}$ ) but the low dominant frequency in sound concrete (around $3 \mathrm{kHz}$ ).

2. Wave velocity: Wave velocity travels slowly (less than $2000 \mathrm{~m} / \mathrm{s}$ ) in concrete with voids but travels faster in sound concrete (more than $2500 \mathrm{~m} / \mathrm{s}$ ). 
This work was supported under the University Research Funding (IPSR/RMC/UTARRF/2017$\mathrm{C} 2 / \mathrm{L} 02)$.

\section{References}

1. Krauser, L.B., 2007. Glossary of Post-Tensioning Terms. General Technologies, INC.

2. Punmia, B. C., Jain, A. K., \& Jain, A. K. (2003). Basic civil engineering. Firewall Media.

3. Neff, T. (2012).New Specifications for Grouting. ASPIRE, Fall, Precast/ Prestressed Concrete Institute, Chicago, Ill. p 52.

4. Pacheco, A. R., Schokker, A. J., Volz, J. S., \& Hamilton III, H. R. (2011). Linear Polarization Resistance Tests on Corrosion Protection Degree of Post-Tensioning Grouts. ACI Materials Journal, 108(4).

5. Whitmore, D., \& Lasa, I. (2014). Cable Impregnation for Post-Tension Grouting Problems. In Transportation 2014: Past, Present, Future-2014 Conference and Exhibition of the Transportation Association of Canada//Transport 2014: Du passé vers l'avenir-2014 Congrès et Exposition de'Association des transports du Canada.

6. Muszynski, L. C., Chini, A. R., \& Andary, E. G. (2003). Evaluating nondestructive testing techniques to detect voids in bonded post-tensioned ducts. ME Rinker Sr. School of Building Construction, University of Florida.

7. Jiang, T., Kong, Q., Wang, W., Huo, L., \& Song, G. (2016). Monitoring of grouting compactness in a post-tensioning tendon duct using piezoceramic transducers. Sensors, 16(8), 1343.

8. Kamada, T., Uchida, S., Tsunoda, H., \& Sato, K. (2012). Non-Destructive Evaluation Methods for Grouting Condition in Tendon Ducts in Existing Prestressed Concrete Bridges (Japanese Title: 実橋梁 PC 林での非破壊試験による PC グラウト充填評価方法に関する研究). Journal of Japan Society of Civil Engineers, Ser. E2 (Materials and Concrete Structures), 68, 238-250.

9. Liu, K. F., Chai, H. K., Mehrabi, N., Yoshikazu, K., \& Shiotani, T. (2014). Condition assessment of PC tendon duct filling by elastic wave velocity mapping. The Scientific World Journal, 2014.

10. Osawa, S., Shiotani, T., Kitora, H., \& Momiyama, Y. (2014, September). Damage visualization of imperfectly-grouted sheath in PC structures. In 31 st Conference of the European Working Group on Acoustic Emission, German Society for Non-Destructive.

11. Lee, F. W., Lim, K. S., \& Chai, H. K. (2016). Determination and extraction of Rayleigh-waves for concrete cracks characterization based on matched filtering of center of energy. Journal of Sound and Vibration, 363, 303-315.

12. Aggelis, D. G., Shiotani, T., \& Polyzos, D. (2009). Characterization of surface crack depth and repair evaluation using Rayleigh waves. Cement and Concrete Composites, 31(1), 77-83.

13. Al Wardany, R., Rhazi, J., Ballivy, G., Gallias, J. L., \& Saleh, K. (2004). Use of Rayleigh wave methods to detect near-surface concrete damage. In 16th WCNDT.

14. Lin, C. H., Lin, C. P., Dai, Y. Z., \& Chien, C. J. (2017). Application of surface wave method in assessment of ground modification with improvement columns. Journal of Applied Geophysics, 142, 14-22. 
15. In, C. W., Kim, J. Y., Kurtis, K. E., \& Jacobs, L. J. (2009). Characterization of ultrasonic Rayleigh surface waves in asphaltic concrete. NDT \& E International, 42(7), 610-617.

16. Nasseri-Moghaddam, A., Cascante, G., \& Hutchinson, J. (2005). A new quantitative procedure to determine the location and embedment depth of a void using surface waves. Journal of Environmental \& Engineering Geophysics, 10(1), 51-64.

17. Jones, R. (1962). Surface wave technique for measuring the elastic properties and thickness of roads: theoretical development. British Journal of Applied Physics, 13(1), 21.

18. Ballard Jr, R. F. (1964). Determination of soil shear moduli at depths by in-situ vibratory techniques (No. AEWES-Misc-Paper-4-691). ARMY ENGINEER WATERWAYS EXPERIMENT STATION VICKSBURG MISS.

19. Wave2000, Cyber-Logic, Inc., New York, http://www.cyberlogic.org. 